\title{
The Role of Primary School Composition in the Trajectories of Internalising and Externalising Problems across Childhood and Adolescence
}

\author{
Efstathios Papachristou ${ }^{1}$ (D) Eirini Flouri ${ }^{1} \cdot$ Emily Midouhas $^{1} \cdot$ Glyn Lewis $^{2} \cdot$ Heather Joshi $^{1}$
}

Published online: 21 September 2019

(C) The Author(s) 2019

\begin{abstract}
There is little research on the role of school and its composition in explaining individual children's psychological outcomes. This study examined for the first time the role of several primary-school compositional characteristics, and their interactions with individual level characteristics, in the development of two such outcomes, internalising and externalising problems, at ages 7, 11 and 14 years in 4794 children in England participating in the Millennium Cohort Study. Using hierarchical (multilevel) linear models, we found that, even after adjusting for individual and family characteristics, children in schools with higher proportions of pupils eligible for free school meals had more externalising problems. In general, children with special educational needs, lower academic performance, more distressed mothers, and those in non-intact families had more internalising and externalising problems. Our results underline the importance of targeting schools with less affluent overall intakes, but also highlight the key role of individual and family characteristics in the development of their pupils' psychological functioning.
\end{abstract}

Keywords England $\cdot$ Externalising problems $\cdot$ Internalising problems $\cdot$ Millennium cohort study $\cdot$ School composition $\cdot$ School effects

\section{Introduction}

School is considered the most important extra-familial context for children. They spend great amounts of time in schools, where they share teachers and social norms, and interact with peers. There is some evidence for the positive role of certain characteristics of this context in children's health outcomes. Such characteristics include a higher socio-economic status (SES) intake, small classes, good teachers and effective classroom and school management which allow for better and more individualised instruction (Bonell et al. 2013; Milkie and Warner 2011; Richmond and Subramanian 2008; Sellström and Bremberg 2006; West et al. 2004). There is also evidence that these school characteristics can affect indirectly

Efstathios Papachristou and Eirini Flouri are Joint first authors

Efstathios Papachristou

Efstathios.papachristou@ucl.ac.uk

1 Department of Psychology and Human Development, UCL Institute of Education, University College London, 25 Woburn Square, WC1H 0AA, London, UK

2 Division of Psychiatry, University College London, London, UK children's and adolescents' psychological outcomes. For example, they can impact on individual children's academic performance (Konstantopoulos and Borman 2011; Nye et al. 2004; Rumberger and Thomas 2000), which is, in turn, associated with self-esteem and academic self-concept (Cvencek et al. 2018) as well as low levels of internalising and externalising problems (Van der Ende et al. 2016). However, there is relatively little research on the direct role of schools and their characteristics in explaining differences in individual pupils' mental health. In this study we sought to fill this gap by examining the role of primary school composition in the levels of internalising and externalising problems from midchildhood to mid-adolescence (ages 7 to 14 years). Building on evidence suggesting that the developmental trajectories of these problems can vary substantially across childhood and adolescence (Flouri et al. 2018), we also aimed to explore the role of primary school composition in dampening, or conversely, exacerbating the influence of individual characteristics on these trajectories.

To date, the main school compositional characteristics that have been associated with key outcomes in youth are ethnic density and ethnic diversity (both related to ethnic composition), academic performance and SES. School-level ethnic diversity (heterogeneity) is typically quantified as the 
probability that two randomly selected pupils from the same school are of different ethnic origin (Benner and Yan 2015). Benner and Crosnoe (2011), who examined the roles of within-school ethnic diversity and ethnic density [also known as ethnic congruence; the proportion of co-ethnics in a school (Benner and Graham 2007; Fleischmann et al. 2012)] in children's outcomes at school entry, showed cognitive benefits for ethnic diversity and emotional benefits for ethnic density (Benner and Crosnoe 2011). They, and others (Gurin et al. 2004), argue that in many ways diversity provides opportunities for valuable cognitive exercise, and should therefore promote academic outcomes; cognitive growth is fostered when individuals encounter experiences and demands that they cannot completely understand or easily meet, such as those brought about by interactions with peers from other ethnicities (Pickett and Wilkinson 2008). Ethnic density, on the other hand, is generally associated with higher levels of social support and a reduction of exposure to racism by dispelling prejudices. For example, reviewing research examining the role of community (neighbourhood) ethnic composition, Shaw et al. (2012) report that members of most ethnic minority groups have better mental health when they live in neighbourhoods with higher proportions of people of the same ethnicity, a phenomenon termed the 'ethnic density effect' and seen in educational contexts too (Gieling et al. 2010).

With respect to school-level academic performance, it seems that children attending lower-performing schools have higher levels of behavioural problems, such as delinquent behaviour (Dudovitz et al. 2018; Wong et al. 2014) and emotional symptoms (E. Goodman et al. 2003), for two main reasons. First, schools promoting academic achievement foster behaviours and habits that may lead to an improved future outlook and less risk taking (Kelly et al. 2005). Second, school-level performance is usually a good proxy for school culture and school connectedness (or school belonging) linked, respectively, to lower levels of externalising and internalising problems. A supportive school culture can isolate children from deviant peers in other schools while also altering opportunities and motivations to engage in risky behaviours by facilitating and enforcing positive peer interactions (Dudovitz et al. 2018). School connectedness, on the other hand, can protect from the effect of risk factors for depression, such as poor family relationships and negative life events (Millings et al. 2012), although with some caveats. Anderman (2002), for example, showed that aggregate school belonging was related positively to individual pupils' academic achievement, but also, counterintuitively, to self-reported social rejection and academic and social problems at school. He suggested (but did not test) that in schools in which many pupils feel that they do belong, those who do not belong may experience more social rejection and problems in school.

Finally, regarding SES, there is a well-documented association between various indicators of socioeconomic disparity at the individual level and child and adolescent mental health (Reiss 2013). However, despite some evidence for an association between school-level poverty and emotional and behavioural problems in childhood (Flouri and Midouhas 2016; Midouhas 2017), the relationship between school-level SES and child and adolescent mental health remains largely unclear. Studies drawing upon ecological theories to examine the importance of individual and school-level SES in school misbehaviour, crime and misconduct (Stewart 2003; Wilcox et al. 2006) identify different effects for individual and contextual SES. Stewart (2003), for example, found a significant effect for individual, but not school level, poverty on misbehaviour, but suggested that economic inequality within the school, rather than school-level SES, might be a better predictor of misbehaviour. Such a pattern of relationships would be in line with predictions from, and findings in line with, the theory of relative deprivation (Stouffer et al. 1949). According to this theory, being relatively deprived in comparison to a reference group causes stress (Winkleby et al. 2006), which can in turn affect health negatively (Yngwe et al. 2003). A 2012 meta-analysis of the impact of relative deprivation on a range of outcomes provided conclusive evidence that one's perception of their relative injustice compared to a welldefined reference group -school, neighbourhood, or othercan impact significantly on mental health (Smith et al. 2012). In educational settings, the Big-Fish-in-Little-Pond effect (Marsh and Hau 2003) similarly predicts that in contexts where social comparisons result in negative self-evaluations, self-concept suffers (Dicke et al. 2018). However, there is also evidence for the reverse. For example, Martens et al. (2014) who examined the effect of similar cross-level interactions on health and education outcomes found that, as expected, poor children overall fared worse than their less poor counterparts. However, neighbourhood-level poverty had a moderating role in that relationship, such that poor children in wealthier neighbourhoods had better outcomes, at least in some of the domains examined, in adolescence. This pattern of relationships is in line with an alternate theoretical model, also motivating several studies on compositional effects, the collective resources model (Macleod and Davey Smith 2003; Pearce and Davey Smith 2003; Stafford and Marmot 2003). According to this, social inequalities in outcomes do not stem from one's relative position in the social hierarchy, but rather from absolute material deprivation. This is turn suggests that poor individuals in poorer contexts do worse than their counterparts in less poor contexts because their lack of resources at the individual-level combines with deprived social resources and neglected infrastructure at the community-level. There are of course other, non-causal, explanations for the association between school-level SES and individual pupils' mental health. For example, schools with higher proportions of disadvantaged pupils have higher rates of bullying and victimisation (Jansen et al. 2012), greater exposure to parental mental illness 
and less parental involvement, which are all, in turn, associated with mental ill-health (Arseneault et al. 2010; Flouri and Buchanan 2003; Wang and Sheikh-Khalil 2014).

Regardless, even when seen as non-causal, the relationship between school's social context and individual pupils' outcomes is usually interpreted through a sociological lens. However, another theoretical framework that can be used to understand this relationship is provided by Bronfenbrenner's bioecological model and Sameroff's transactional model (Bronfenbrenner 1979; Bronfenbrenner and Morris 1998; Sameroff 1975). Bronfenbrenner conceptualised ecological systems that describe different aspects of an environment, each nested within the others, which interact to influence a child's growth and development. The main systems include a) the child herself and what she brings to the world with her, e.g. personality characteristics -termed micro system; b) her immediate settings, e.g. family -termed meso system; c) her more distal settings, e.g. the neighbourhood -termed exo system; and d) the general society in which she lives -termed macro system. Similarly, Sameroff (1975) posited that development is driven by the complex interplay between a child's inherent characteristics, family characteristics and her economic, social and community resources.

The common underlying theme of both models is that they consider outcomes to be driven by neither the individual nor the context alone; instead, outcomes are seen as the product of the relative and interactive effects of both individual and contextual factors. In addition, both models distinguish between interactions of factors that are in a child's immediate environment (termed proximal processes or influences) from those affecting the child less directly (distal processes or influences). While proximal processes are the primary mechanism for development, both models emphasise both the importance of interactions between the various systems and the impact of distal influences on proximal processes, which in turn shape development. Researchers studying pupil outcomes using either model as a conceptual tool should thus be expected to examine the role of interactions between systems but also, importantly, how distal (e.g., school) processes can drive more proximal processes, in turn determining outcomes. To an extent this has been done in studies that, motivated by such ecological models, examined the role of school-level characteristics in academic and social outcomes (Benner et al. 2008; Benner and Yan 2015). For example, Benner and Yan (2015) found that greater classroom ethnic diversity promotes parental involvement, which is in turn associated with children's interpersonal skills and reading achievement. Earlier Benner et al. (2008) demonstrated that structural characteristics of families and schools, including living arrangements, schoollevel SES, school size, and others, influenced proximal processes within each of these settings, which in turn, influenced academic attainment.
An additional key system in Bronfenbrenner's bioecological model which was considered more recently (Bronfenbrenner and Morris 2006) is the chrono system, which encompasses the dimension of time. Elements within this system can be either external, such as the timing of a parent's death, or internal, such as the normative changes that occur with the ageing of a child. This element of the model is particularly relevant for the study of pupil mental health across childhood and adolescence because the transition from childhood to adolescence is a critical developmental period (Sawyer et al. 2018). Importantly, the transition to adolescence coincides with another important transition: the one to secondary school. However, to our knowledge, this dimension is yet to be incorporated fully in studies applying an ecological lens on the relationship between school characteristics - and their interactions with the microsystem - and pupil mental health. Considering this element explicitly was an additional contribution of this study.

\section{The Present Study}

In light of this literature, we explored the role of primary school composition in children's trajectories of internalising and externalising problems from mid-childhood to midadolescence in England. We also investigated its role in changing children's likelihood of following the trajectories expected on the basis of their individual and family characteristics. The features of school composition we considered were ethnic diversity, school-average academic performance [measured with Key Stage 1 (KS1) scores], as well as the proportion of children with free school meal (FSM) eligibility (as a proxy of SES), English as an additional language, and special educational needs (SEN). Eligibility for FSM is much used in UK research as a proxy for SES, as it reflects family eligibility to income tested benefits (Ilie et al. 2017); pupils are entitled to FSM if their parents receive certain means-tested benefits or tax credits subject to a gross household income ceiling. We tested cross-level interactions between a) school-average KS1 performance b) proportion of pupils in the school eligible for FSM and c) proportion in the school with SEN, and the equivalent individual characteristics (i.e. child's KS1 score, child's FSM eligibility and child's SEN status) on the children's trajectories. We expected that less disadvantaged socioeconomic intake and less ethnic diversity would be associated with lower levels of both internalising and externalising problems in childhood. Regarding cross-level interactions, we expected that low-SES children (those eligible for FSM) in high-SES schools (schools with low proportion of children with FSM eligibility) would have more internalising problems. 


\section{Methods}

\section{Sample}

We used data from the Millennium Cohort Study (MCS), a population-based cohort of children born in the UK over 12 months from 1 September 2000 (Joshi and Fitzsimons 2016). The children in the MCS were around 9 months old at Sweep 1, and 3, 5, 7, 11 and 14 years old at Sweeps 2-6, respectively. At the six sweeps, the numbers of productive families were $18,522,15,590,15,246,13,857,13,287$ and 11,714. Ethical approval was gained from NHS Multi-Centre Ethics Committees. Parents gave informed consent before interviews took place, and from age 11 children gave assent.

When the children were aged 7 , information was also collected from the cohort children's class teachers using a self-completion postal questionnaire. In total, 7235 teachers in 4969 schools were contacted to take part in the survey. Of those, 5364 teachers $(74.1 \%)$ from 3981 schools $(80.1 \%)$ completed and returned a questionnaire for 8876 children. Ethical approval for the teacher survey was given by the Northern and Yorkshire Multi-Centre Research Ethics Committee (MREC) of the NHS (Huang and Gatenby 2010). Further approvals were sought and given for carrying out the survey in schools in each UK country. For England, the survey was approved by the Star Chamber in the Department for Children, Schools and Families; for Wales, by the Schools Workforce Advisory Panel; for Scotland, by the Directors of Education in the Local Educational Authorities; and for Northern Ireland, no formal approval was needed.

We used data from sweeps 4 (age 7) to 6 (age 14). The flow chart illustrates the process followed to derive the analytic sample of this study $(n=4974$; we count only one child per family, i.e., singletons and firstborn twins or triplets) and associated attrition (Fig. 1). Our analytic sample included those with available information on at least one of the school compositional and structural characteristics considered at age 7 , and all school information was obtained from the School Data Unit at the Department for Education. Since that information was about pupils in state schools in England, those from the other three UK countries as well as those in private schools had to be excluded. KS1 assessment data in England are collected at the end of Year 2 (normally the year in which pupils reach age 7) and therefore we also excluded two children who were not in Year 2 during that academic year. Finally, we excluded children attending special schools at ages 7 or 11 .

\section{Measures}

\section{Internalising and Externalising Problems}

Internalising and externalising problems are the two main dimensions that have been widely used to characterise the structure of mental health in children and adolescents (Cicchetti and Toth 2014). Available evidence suggests that they are related to several common psychiatric disorders, including depression, anxiety disorders, substance use disorder, and antisocial personality disorder (Krueger et al. 2001). We assessed internalising and externalising problems in MCS using the parent-reported Strengths and Difficulties Questionnaire (SDQ) at ages 7, 11 and 14 years. The SDQ is a short, psychometrically-valid and widely-used behavioural screening tool (R. Goodman 1997). It comprises 25 items which form five scales: emotional symptoms, conduct problems, hyperactivity/inattention, peer problems and prosocial behaviour. In line with recommended practice for community samples (A. Goodman et al. 2010), the internalising problems scale comprises the 10 items from the emotional and peer problems subscales, and the externalising problems scale the 10 items from the hyperactivity and conduct problems subscales. Scores on the internalising and externalising problems scales range from 0 to 20 with higher scores indicating more serious problems or symptoms. The sum of the two scales yields a total difficulties score. In our analytic sample both internalising and externalising problems scales showed satisfactory internal consistency (Cronbach's alpha values were 0.71 and $0.79,0.77$ and 0.80 , and 0.78 and 0.81 , at ages 7 , 11 and 14 , respectively).

\section{School Compositional Characteristics}

School compositional characteristics obtained from the School Data Unit at the Department for Education applied to state-maintained schools during January 2008 (corresponding with MCS sweep 4, age 7) and were banded into deciles based on all primary schools in England. School-average KS1 scores were averaged for English, Maths and Science across pupils. School socioeconomic composition was based on the percentage of pupils who were eligible for FSM. Additional school characteristics included the percentage of pupils whose first language was known or believed to be English and the percentage of children with SEN (without statements; a statement of SEN sets out the child's needs and the help they should receive. It is reviewed every year to make sure that any extra support given meets the child's needs). Finally, we created a census-based measure of school-level ethnic heterogeneity using Greenberg's diversity index (Greenberg 1956), which utilises a formula that measures the probability that 


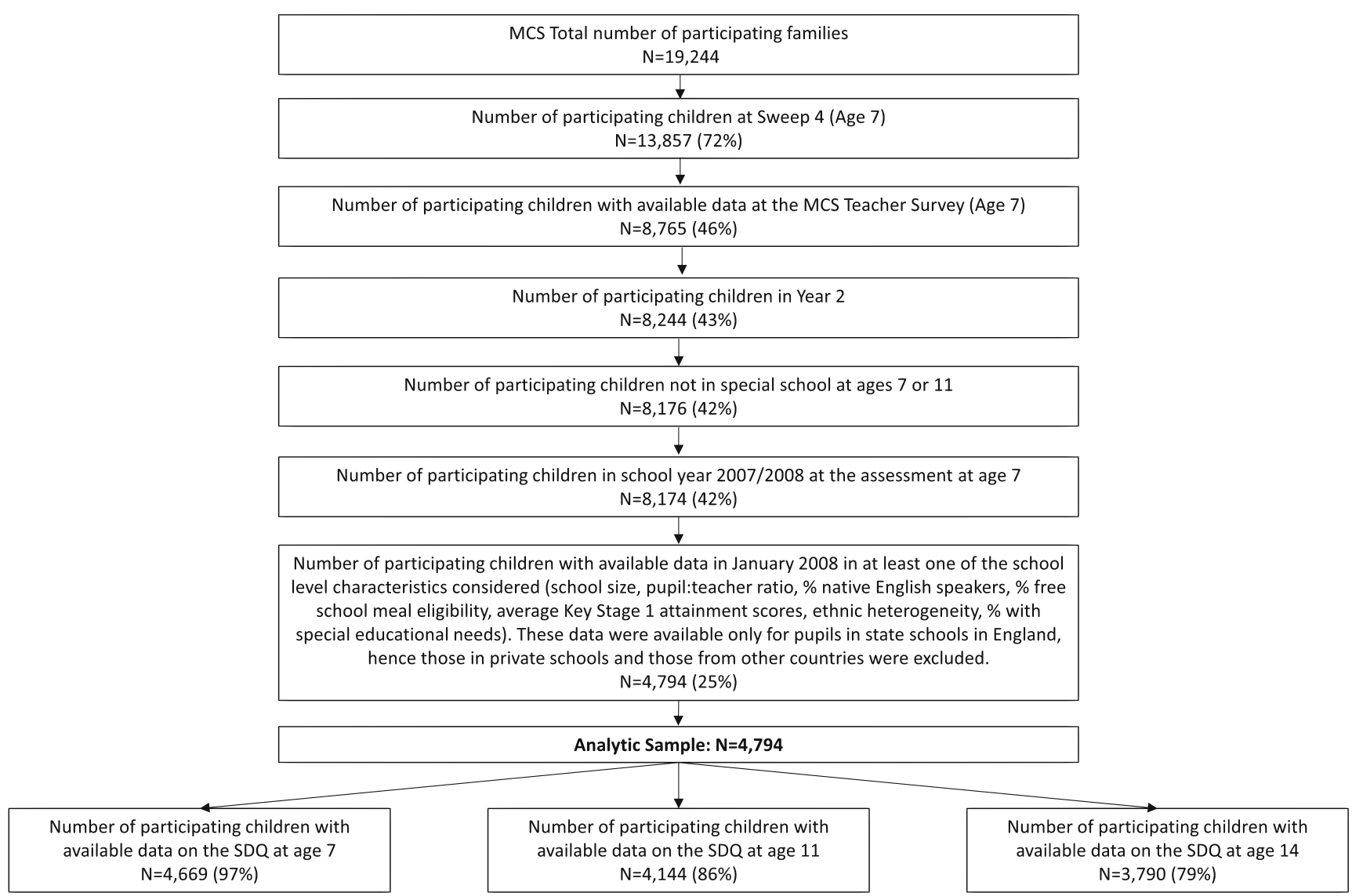

Fig. 1 Flow chart of the study

two randomly chosen individuals from a population in a given area will have the same ethnicity. All sensitive data were linked with MCS data in a secure environment using the unique anonymised reference number of each child's school.

\section{Covariates}

Information on individual academic performance (measured with the child's KS1 average score) and FSM eligibility was collected during the January 2008 census and obtained from the National Pupil Database. We also adjusted for individual and family-level characteristics (at baseline, age 7 years) that are known to be associated with both selection into schools and psychological functioning in youth: age (in months), gender, SEN status, ethnicity (the standard eleven Census categories as listed in Table 3), maternal education (university degree or not), family structure (living with both biological parents or not) and maternal psychological distress [using the Kessler K6 (Kessler et al. 2002)] (Flouri et al. 2018). The $\mathrm{K} 6$ is a validated six-question instrument that was developed to estimate the prevalence of serious mental illness in general population samples (Kessler et al. 2010). In MCS, mothers were asked how often during the past 30 days they felt: 'so depressed that nothing could cheer you up', 'hopeless', 'restless or fidgety', 'that everything was an effort', 'worthless' and 'nervous'. Each item is scored on a five-point Likert scale, from 'None of the time' (0) to 'All of the time' (4).We also considered two structural school characteristics, the headcount of pupils - as a measure of school size - and the pupil:teacher ratio which was computed by dividing the pupil headcount by the number of teachers.

\section{Statistical Analysis}

First, we examined the distribution of internalising and externalising problems and the school, individual and family characteristics of the analytic sample at baseline (age 7). Next, we ran a sample bias analysis to examine differences in individual and family characteristics between children included in the analytic sample $(N=4794)$ and the non-analytic sample $(N=3380)$. We then ran a series of multilevel linear models (MLMs) to examine the associations of school characteristics at age 7 with trajectories of internalising and externalising problems at ages 7, 11 and 14 years. By running MLMs rather than simple fixed effects regression models we accounted for the hierarchical nature of the data with repeated measures (at ages 7, 11 and 14 years) of internalising and externalising 
problems for children, i.e. by having occasions (level 1) nested in children (level 2), thus obtaining more robust standard errors for the regression coefficients. We did not consider for this analysis (although we did perform a supplementary analysis, see under Sensitivity Analyses below) a third level (children nested within schools) in the MLMs because the degree of clustering of MCS children within school was not adequate. In the analytic sample, the majority of schools (66\%) provided information for a single MCS child, $14 \%$ of schools for two MCS children and only $20 \%$ of schools for three or more, with the average MCS pupil count within a single school being 2.1.

In the first set of MLMs (Model A), we examined the crude associations between school compositional and structural characteristics with the trajectories of externalising and internalising problems. In the next set (Model B), we adjusted further for the individual and family covariates. We tested for multicollinearity between the covariates by using variance inflation factor (VIF) values [VIF values $>4$ indicate multicollinearity (Fox 2016)]. In the third set of analyses (Model C), we further examined the effect of cross-level interactions on the trajectories of externalising and internalising problems for those characteristics that were measured at both school and child levels; these included FSM eligibility, SEN status and KS1 score. We did not estimate cross-level interactions for English as an additional language on the trajectories of internalising and externalising problems because very few MCS children were reported to be non-English speakers at age 7 (all MCS children were born in the UK). Similarly, we did not estimate cross-level interactions between individual and school-level ethnicity because the variables used to capture school-level ethnic density had too many missing values to be reliably imputed ( $>50 \%)$. Although there were many cases where unmeasured school effects could not be disentangled from individual child characteristics due to the low degree of clustering of pupils within schools, we did attempt to estimate random effects for schools in a sensitivity analysis (reported below). For this analysis we tested the proportion of variance in the outcomes that is explained by commonalities in children attending the same school by introducing a 3rd level (children nested within schools) to the MLMs.

Missing data on outcome measures and covariates in the analytic sample were handled using multiple imputation by chained equations (Azur et al. 2011). We generated 20 imputed datasets using linear, logistic and ordered regressions depending on the scale of measurement of the variables being imputed, and performed complete-data analyses using Rubin's combination rules to consolidate the obtained individual estimates into a single set of multiply imputed estimates. All MLMs took into account the stratified sample design of MCS by including the eight strata (England-disadvantaged, Wales-advantaged, Wales-disadvantaged, Scotlandadvantaged, Scotland-disadvantaged, Northern Irelandadvantaged, and Northern Ireland-disadvantaged) as dummy variables (England-advantaged was the reference category and hence excluded) in the fixed part of the models [although the analytic sample were all observed in England at age 7, a small number of cases $(N=64)$ had moved into England from the other countries since the original sampling and hence were included in the fixed part of the MLMs with their varying initial sample probabilities]. Age was grand mean centred (at 127.79 months, i.e. 10.6 years) in all MLMs. Where appropriate, i.e., for those models in which significant associations between school compositional characteristics and the outcomes were found, we re-ran our analyses after rescaling and standardisation of the independent variables to obtain a measure of the sizes of the fixed effects. We rescaled the predictors by subtracting the mean value of each continuous independent variable from their respective raw value and divided by two standard deviations. By dividing by two standard deviations the interpretation of the regression coefficients of continuous independent variables is directly comparable to that obtained for the untransformed binary predictors because a binary variable -with equal probabilities- has a mean of 0.5 and a standard deviation of 0.5 (Gelman 2008). In all analyses, we used study-specific weights to account for the disproportionate attrition of participants in MCS. In line with a Bonferroni correction for critical $p$-values we accounted for multiple testing in the models by considering $p$-values of $<0.01$ as significant. Analyses were run using Stata/SE 15.1 (StataCorp 2011) and MLwiN 3.02 (Charlton et al. 2018).

\section{Results}

\section{Descriptive Statistics}

The baseline (age 7) characteristics of children in the analytic sample $(N=4794)$ and the percentage of missing data across variables are summarised in Table 1. At age 7, children (51\% male) were on average 86.72 months old $(\mathrm{SD}=2.92)$, with average internalising and externalising scores of 2.78 ( $\mathrm{SD}=$ $2.80)$ and $4.72(\mathrm{SD}=3.50)$, respectively. The average KS1 score of the analytic sample was $5.57(\mathrm{SD}=2.83)$. The majority of children comprising the analytic sample were White $(N=3921 ; 82 \%)$, lived with both biological parents $(N=$ $3486 ; 73 \%)$ and did not have SEN $(N=3450 ; 72 \%)$. Moreover, $18 \%(N=798)$ had mothers with a university degree and $16 \%(N=648)$ were eligible for FSM. In comparison, the children in the non-analytic sample (those in schools outside England and those in English private schools; $N=$ 3380) had lower mean internalising $(\mathrm{M}=2.42, \mathrm{SD}=2.63)$ and externalising $(\mathrm{M}=4.37, \mathrm{SD}=3.48)$ scores (both $p$-values $<0.001$ ), and mothers with lower levels of psychological distress $(\mathrm{M}=2.83, \mathrm{SD}=3.68, p<0.001)$. They were also more likely to have mothers with a university degree $(22 \%$; $p<0.001)$, less likely to have SEN (75\%; $p=0.02)$ and more 
Table 1 Baseline sample (age 7, in around 2008) and school characteristics (in January 2008) of the analytic sample ${ }^{*}(N=4794)$ (unweighted data)

\begin{tabular}{|c|c|c|c|}
\hline Continuous variables & Mean & Standard Deviation & $\%$ Missing data \\
\hline Child's internalising problems & 2.78 & 2.80 & 2 \\
\hline Child's externalising problems & 4.72 & 3.50 & 2 \\
\hline Child's average Key Stage 1 score & 5.52 & 2.89 & 13 \\
\hline Child's age (months) & 86.72 & 2.92 & 0 \\
\hline Maternal psychological distress & 3.15 & 3.82 & 4 \\
\hline School size (deciles) & 6.82 & 2.70 & 2 \\
\hline School's pupil teacher ratio (deciles) & 6.19 & 2.67 & 2 \\
\hline School's proportion of native English speakers (deciles) & 2.58 & 1.19 & 2 \\
\hline $\begin{array}{l}\text { School's proportion of free school meal eligibility } \\
\text { (deciles) }\end{array}$ & 5.51 & 2.79 & 6 \\
\hline $\begin{array}{l}\text { School's proportion of children with special educational } \\
\text { needs (without statement) (deciles) }\end{array}$ & 5.38 & 2.81 & 2 \\
\hline School's average Key Stage 1 score (deciles) & 5.57 & 2.83 & 9 \\
\hline School's ethnic heterogeneity & 5.61 & 2.78 & 21 \\
\hline Categorical variables & $\mathrm{N}$ & $\%$ & $\%$ Missing Data \\
\hline Gender, female & 2370 & 49 & 0 \\
\hline Child's mother has university degree & 798 & 18 & 5 \\
\hline Child eligible for free school meals & 648 & 16 & 13 \\
\hline Child does not have special educational needs & 3450 & 72 & 0 \\
\hline Child's ethnicity & & & 0 \\
\hline White & 3921 & 82 & \\
\hline Mixed & 161 & 3 & \\
\hline Indian & 142 & 3 & \\
\hline Pakistani & 251 & 5 & \\
\hline Bangladeshi & 78 & 2 & \\
\hline Other Asian & 41 & 1 & \\
\hline Black Caribbean & 60 & 1 & \\
\hline Black African & 94 & 2 & \\
\hline Other Black & 15 & 0 & \\
\hline Chinese & 6 & 0 & \\
\hline Other ethnic group & 24 & 1 & \\
\hline Child lives with both biological parents & 3486 & 73 & 0 \\
\hline
\end{tabular}

${ }^{*}$ See flow chart (Fig. 1) likely to be White $(95 \% ; p<0.001)$, reflecting the higher proportion white in the population outside England. However, there was no evidence for a difference between the two groups regarding their mean age, gender or the proportion living with both biological parents (all $p$-values $>0.05$ ).

\section{Bivariate Associations between the Main Measures}

Table 2 summarises the bivariate associations between the school compositional measures. The Pearson's correlation coefficients were all statistically significant. The strongest associations were between ethnic heterogeneity and proportion of native English speakers $(\mathrm{r}=-0.78, p<0.01)$, between average KS1 scores and proportion of children with FSM eligibility $(\mathrm{r}=-0.63, p<0.01)$ and between proportion of children with SEN and proportion of children with FSM eligibility $(r=0.55$, $p<0.01)$.

\section{School Compositional Characteristics and Children's Internalising Problems}

Table 3 presents the results of MLMs examining the relationship between school compositional characteristics and internalising problem trajectories at ages 7, 11 and 14 years. All the regression coefficients presented are unstandardised, unless otherwise stated. Before adjusting for covariates (Model A), attending a school with a higher proportion of children with FSM eligibility, a larger share of children with 
Table 2 Pearson's correlation coefficients between school characteristics at baseline (age 7)

\begin{tabular}{|c|c|c|c|c|c|c|c|}
\hline & 1. & 2. & 3. & 4. & 5. & 6. & 7. \\
\hline 1. School size (deciles) & 1.00 & & & & & & \\
\hline 2. School's pupil teacher ratio (deciles) & $0.40^{*}$ & 1.00 & & & & & \\
\hline 3. School's proportion of native English speakers (deciles) & $-0.31 *$ & $-0.04 *$ & 1.00 & & & & \\
\hline 4. School's proportion of free school meal eligibility (deciles) & $0.06^{*}$ & $-0.30 *$ & $-0.35^{*}$ & 1.00 & & & \\
\hline $\begin{array}{l}\text { 5. School's proportion of children with special educational needs (without statement) } \\
\text { (deciles) }\end{array}$ & $0.04 *$ & $-0.17^{*}$ & $-0.20 *$ & $0.55^{*}$ & 1.00 & & \\
\hline 6. School's average Key Stage 1 score (deciles) & $-0.14^{*}$ & $0.20 *$ & $0.26^{*}$ & $-0.63^{*}$ & $-0.54 *$ & 1.00 & \\
\hline 7. School's ethnic heterogeneity & $0.21 *$ & $0.03 *$ & $-0.78^{*}$ & $0.25^{*}$ & $0.11 *$ & $-0.13^{*}$ & 1.00 \\
\hline
\end{tabular}

$* p<0.01$

SEN, and a lower average KS1 score was independently associated with increased levels of internalising problems at the intercept (around age 11 years). ${ }^{1}$ These associations did not, however, survive adjustments for individual and family characteristics (Model B). The cross-level interactions for FSM eligibility, SEN status and academic performance were also not significant (Model C) suggesting that the school's composition did not alter the child's likelihood of following their expected, based on their own characteristics, trajectory of internalising problems. In the fully adjusted model, males, children without SEN, those showing better academic performance, those with less distressed mothers and those living with both biological parents had lower levels of internalising problems at around age 11. The VIF in Model B, which included all the covariates (but not the interactions), ranged from 1.02 to 3.33 (mean VIF $=1.64$ ) suggesting absence of multicollinearity.

\section{School Compositional Characteristics and Children's Externalising Problems}

Table 3 also presents the results of MLMs of the relationship between school compositional characteristics and externalising problem trajectories at ages 7,11 and 14 years. In the baseline model (Model A), attending a school with a higher proportion of children eligible for FSM and lower average academic performance at age 7 was associated with increased levels of externalising problems at around age 11 . School-level FSM eligibility - but not school-average academic performance - retained its significant association with externalising problems after adjustments for children's individual and family characteristics (Model B). The cross-level interactions for FSM eligibility, academic performance and SEN status were not significantly associated with externalising problems (Model C). In this, fully-adjusted,

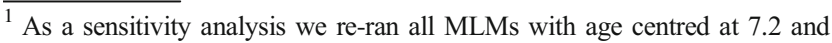
14.3 years. The results remained materially identical, hence the effects of the predictors on the outcomes at age 11 also apply to assessments of internalising and externalising problems at ages -around- 7 and 14 years.
}

model, females, children without SEN, those with more educated and less distressed mothers, those with better academic performance and those living with both biological parents had lower levels of externalising problems at around age 11 . Figure 2 illustrates the significant association between school-level FSM eligibility and externalising problems in the fully adjusted model (Model C). To aid interpretation, we transformed the proportion of FSM eligibility into quintiles and plotted the linearly predicted margins of externalising problem scores across the five FSM-eligibility quintiles.

Moreover, in order to elucidate the relative importance of the proportion of FSM eligibility for the trajectories of internalising problems compared to the remaining individual level characteristics we re-ran this final model after re-scaling the continuous variables and dividing by two standard deviations. The results of this model suggest that, as expected, maternal psychological distress $(b=1.28, \mathrm{SE}=0.09)$, academic performance $(b=-1.35, \mathrm{SE}=0.20)$ and SEN status $(b=-1.03, S E=0.20)$ had the largest effect sizes. The effect size of school-level FSM eligibility $(b=0.52, \mathrm{SE}=0.13$ ) was comparable to the ones yielded for gender $(b=-0.79, \mathrm{SE}=$ 0.07), maternal education $(b=-0.41, \mathrm{SE}=0.10)$ and living with both biological parents $(b=-0.59$. $\mathrm{SE}=0.10)$.

\section{Sensitivity Analyses}

As school poverty can simply reflect the level of socioeconomic disadvantage of the area, in turn associated with mental health at least in adults, we examined neighbourhood and school poverty effects simultaneously. We therefore re-ran the fully-adjusted models for internalising and externalising problems after controlling for poverty in the child's residential neighbourhood [Lower layer Super Output Area (LSOA)], measured using the 2004 Index of Multiple Deprivation (IMD) income deprivation score. ${ }^{2}$ In these new models,

\footnotetext{
${ }^{2}$ In deciles. Note: LSOAs are small geographical units built from groups of Census Output Areas (typically 4-6) and are constrained by the boundaries of the Standard Table wards used for Census outputs. They have, on average, 1500 residents and are generally smaller than wards.
} 


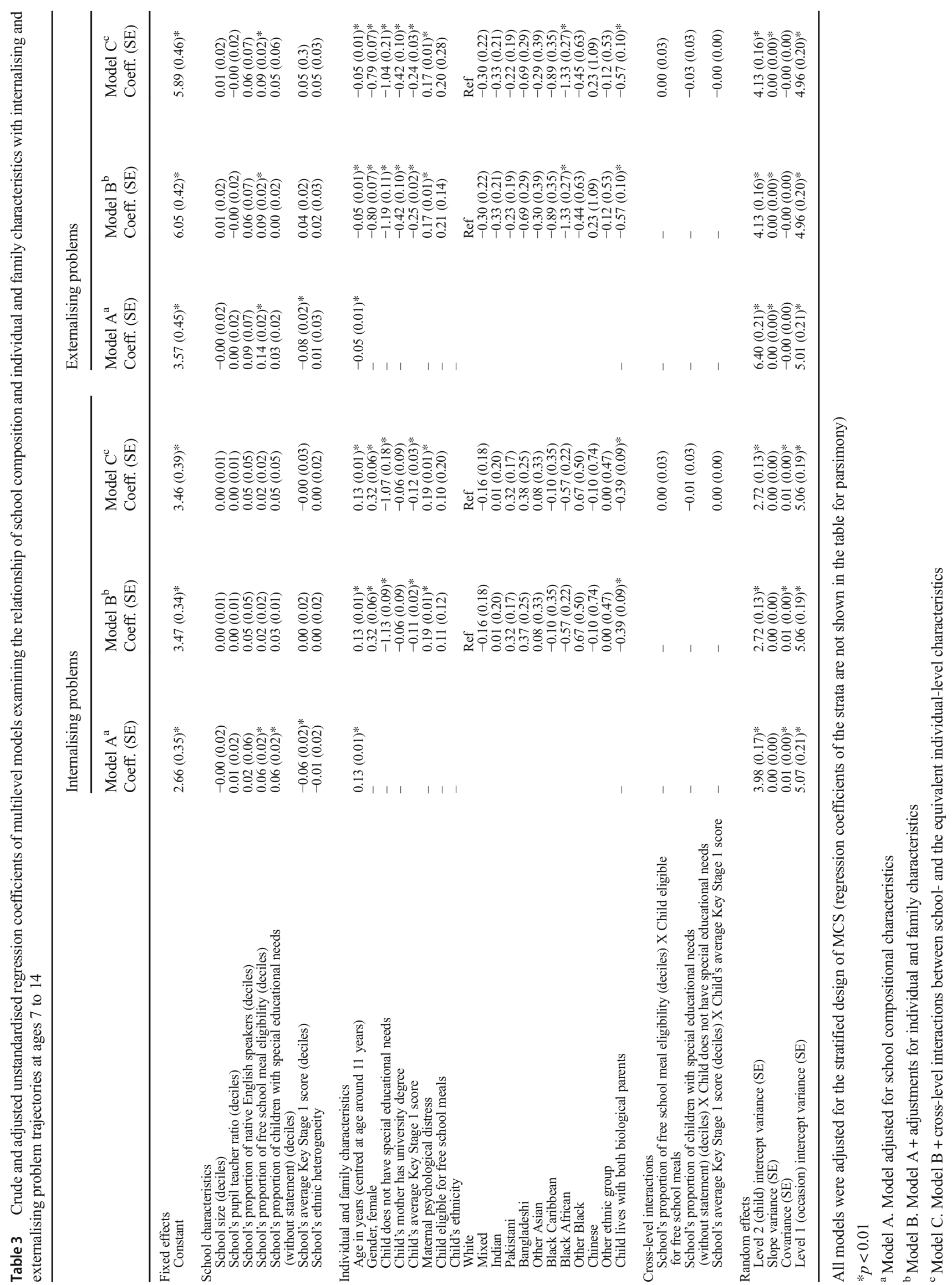




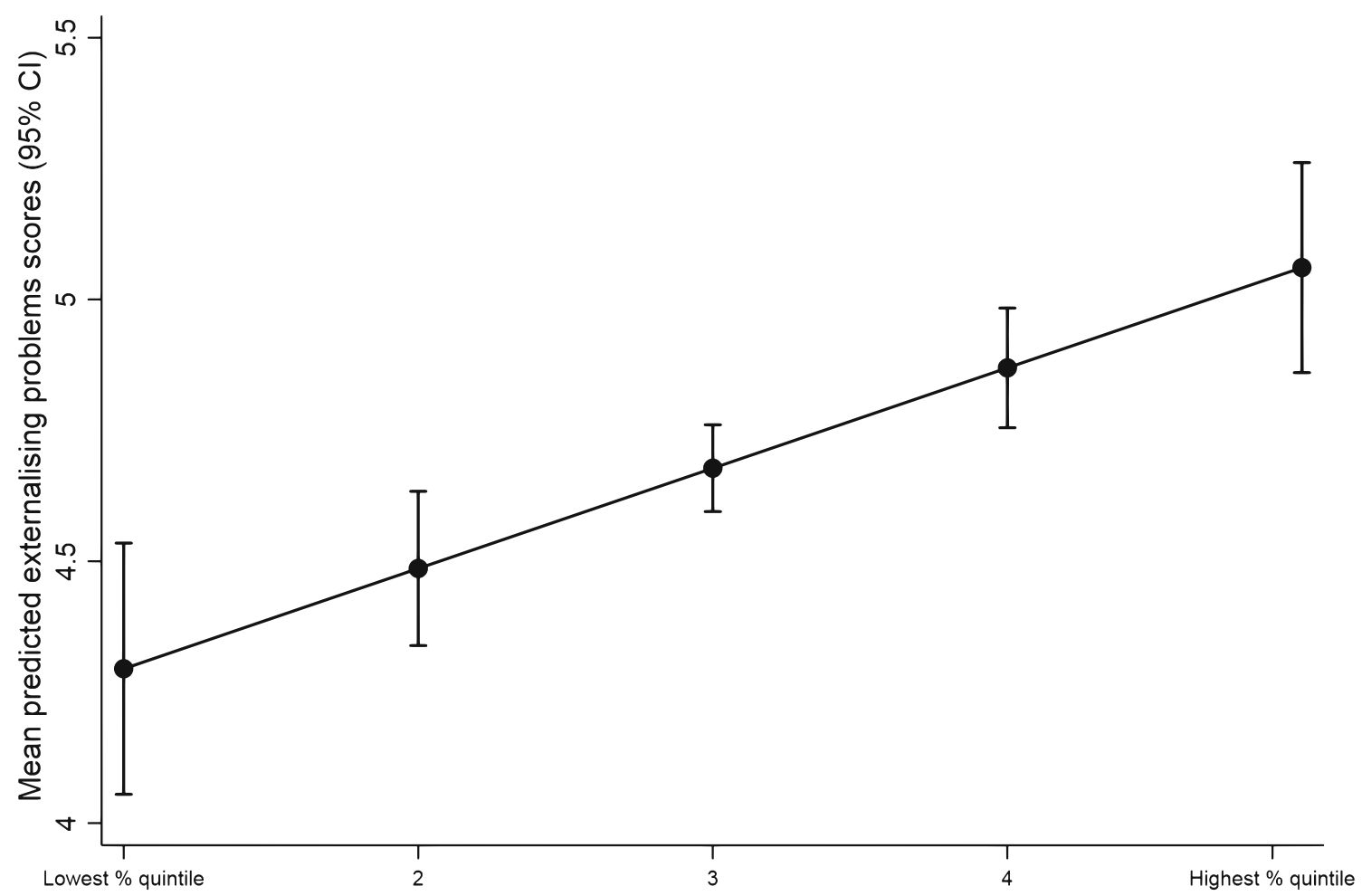

School-level proportion of children with free school meal eligibility in quintiles

Fig. 2 Linear predictive margins of externalising problem scores (95\% CI) by quintile of school-level proportion (\%) of children with free school meal eligibility (Model C)

neighbourhood poverty had a disadvantageous effect on internalising problems $(\mathrm{b}=-0.04, \mathrm{SE}=0.02, p=0.01)$, but a non-significant effect on externalising problems $(b=-0.03$, $\mathrm{SE}=0.02, p=0.15$ ). In the externalising problems model, the effect of school poverty remained significant $(b=0.07$, $\mathrm{SE}=0.02, p=0.002$ ).

We also attempted to address an important study limitation: our inability to account for group level random effects due to the insufficient clustering of children within schools; as discussed, in the analytic sample $66 \%$ of schools provided information for a single MCS child, and the average MCS pupil count within a single school was 2.1. There have been recent attempts to tackle the problem of sparseness of lower-level units per higher level whereby lower-level units are grouped together into larger "synthetic" groups, yielding a larger number of cases per higher-level. However, such clustering strategies introduce artificial within-group heterogeneity by grouping together units which may differ on a host of unobserved characteristics (Clarke and Wheaton 2007). In light of this, we treated schoollevel characteristics at the same level as individual level characteristics in our analysis thus far. Nonetheless, we also tested our approach empirically. First, having added a third level for 'school', we ran two multilevel models - one for each of internalising and externalising symptoms - which accounted for MCS's complex design but did not include any additional explanatory variables. Using this model specification, we calculated the intraclass correlation coefficient (ICC) to estimate the proportion of variance in internalising and externalising symptom trajectories that is explained by commonalities in children attending the same school. The results of the model using internalising problems as the outcome suggested that between-school variation accounted for a mere $1.7 \%$ of the variation in the outcome, yet the variance in the outcome due to children clustering within-school was not statistically significant (variance $=0.16 ; \mathrm{SE}=$ $0.09 ; p=0.06$ ). Using externalising problems as the outcome, the ICC was slightly higher at $4.7 \%$ and the variance in the outcome due to children clustering within-school reached statistical significance (variance $=0.55 ; \mathrm{SE}=0.13 ; p<0.01)$. Following up on this significant finding, we ran a fully adjusted multilevel model for externalising problems including the full list of covariates (Model C). The results of this model remained materially unchanged compared to the estimates (presented earlier) from the model which did not take into account the clustering of pupils within 
schools. These findings suggest that, due to the low degree of clustering of children within schools in MCS, considering the nesting of pupils within school adds an unnecessary layer of complexity to the multilevel models without impacting on the estimates of the regression coefficients.

\section{Discussion}

This is the first study to examine the roles of several primary school composition and cross-level interactions between school composition and child background in trajectories of externalising and internalising problems from mid-childhood to mid-adolescence. The results suggest that, even after adjustments for children's individual and family characteristics, children attending schools with higher proportions of FSM-eligible pupils had more externalising problems throughout childhood and adolescence. If these associations were causal, they would suggest that interventions aiming to reduce socioeconomic inequalities in schools (for example by pursuing policies that work against the segregation of pupils and schools according to SES) have the potential to improve pupils' internalising and externalising problems and, therefore, alleviate some of the burden associated with poor psychological functioning. Nonetheless, we note that some of the individual and family factors we considered appeared to have larger associations with a child's internalising and externalising problems. These included child's special educational needs status and academic performance, maternal psychological distress and family structure. Thus, our study provides further support for the key role of these factors, well-established in the extant literature, in child mental health (Flouri et al. 2018; Oldfield et al. 2017; Weeks et al. 2016). It also provides more evidence about the developmental course of these child mental health difficulties in the general school population from mid-childhood to mid-adolescence. As can be seen in our fully adjusted models, age (centred at around 11 years) had a significant positive effect on the average internalising problem trajectory and a significant negative effect on that for externalising problems. This suggests that, as children reach puberty and enter secondary school, their internalising symptoms increase while their externalising problems (hyperactivity and conduct problems) decrease, in line with what previous literature supports (Angold et al. 1998; Le and Stockdale 2011).

Previous evidence also suggests advantageous effects of school-average academic performance and lower share of pupils with SEN on self-esteem and academic performance (Cvencek et al. 2018; Hienonen et al.
2018), both of which are closely linked with internalising and externalising problems (Van der Ende et al. 2016; Watkins and Melde 2016). Our results too showed significant associations between school-average academic performance and children's internalising and externalising problems at around age 11 (and between share of pupils with SEN and individual children's internalising problems), albeit only before adjustments for key individual and family level covariates. This suggests that the direct effects of these school compositional characteristics on children's psychological outcomes are relatively weak and confounded.

Contrary to our expectations, our study findings offered little support to the theory of relative deprivation (Stouffer et al. 1949) or the Big-Fish-in-Little-Pond effect (Marsh and Hau 2003). The cross-level interactions that we examined were not significant for either internalising or externalising problems, suggesting that the effects of own academic performance, own SEN status or own FSM eligibility did not differ according to the school's average academic performance, proportion of pupils with SEN or share of pupils on FSM. One possibility is that, at primary school, children are not aware of their school's academic reputation, as the 15 year olds studied by Marsh and Hau (2003) may have been. Another possibility however is that these null findings, in particular the ones pertaining to crosslevel interactions between school-level and individual academic performance, ${ }^{3}$ are due to lack of statistical power. Until studies with more power to detect such interaction effects are carried out, we must treat these findings as exploratory.

From the point of view of planning public health interventions, it is important to emphasise the relatively strong impact of the proportion of school FSM eligibility on the levels of externalising problems throughout childhood and adolescence. According to the results of this study, a reduction in school-level FSM eligibility by a single decile is associated with a reduction of 0.1 points on the hyperactivity scale of the SDQ. Albeit this might not appear as a strong effect, it should be interpreted in light of evidence that school-level factors are, generally, weaker predictors of outcomes than individual-level factors (Welsh et al. 1999). In fact, the effect size of school FSM eligibility was comparable to the ones obtained for established individual level risk factors of externalising problems, including low parental education (Huisman et al. 2010) and not living with

\footnotetext{
${ }^{3}$ Own and school's average academic performance were each measured in deciles. Their interaction results in a $10 \times 10$ contingency table ( 81 degrees of freedom). The power of a $\chi^{2}$ test for this interaction is high only when trying to detect medium and large ( $>=0.2$ power $>99 \%)$, but not small $(<=0.1$, power $<80 \%$ ), effect sizes at a 0.01 level of significance.
} 
both biological parents (Luoma et al. 1999). Of course this finding is not to suggest that schools should exhibit favouritism towards more affluent pupils at the selection stage in order to reduce the proportion of pupils eligible for FSM. Rather our findings provide encouraging evidence that interventions targeting poverty at the community level might prove to be effective in reducing externalising problems among pupils of such areas by lowering the number of FSM eligible pupils in local schools. Our findings also suggest that closer monitoring of pupils in schools with a high proportion of FSM eligibility is warranted in order to identify and target externalising problems at an early stage.

Our study has several strengths. The data came from the largest UK birth cohort and covered a wide range of school, family and individual characteristics that we examined in relation to externalising and internalising problems. We also used state-of-the-art statistical procedures to impute missing data and run the analyses. Additionally, by considering simultaneously characteristics at both individual and school levels, we avoided committing the ecological fallacy, whereby inference occurs at the group level (school, in this case), but is actually attributable to confounding by individual factors (Snijders and Bosker 1999). Finally, we tested the effect of cross-level interactions, which has been largely neglected in the extant literature of 'school effects'. By doing so, we were able to test the role of the school's composition in changing an individual pupil's likelihood of following the path of psychological functioning that would have been expected on the basis of their individual and family characteristics.

Nonetheless, our study has limitations too, and our results should be interpreted with these caveats in mind. First, the analytic sample comprised a relatively disadvantaged group of children, which compromises the external validity of our study. Second, we did not have data on the children's secondary schools or on the primary school at age 11 where this had changed. Third, we acknowledge that FSM is not always a good proxy for socio-economic disadvantage because there is evidence that significant numbers of children can experience socio-economic disadvantage of different forms (Ilie et al. 2017; Taylor 2018). Nonetheless, as Taylor (2018) suggests, FSM eligibility comes very close to identifying a disadvantaged group of children. Fourth, we did not control for psychological functioning prior to the study period, i.e. before age 7. Prior differences in internalising and externalising symptoms might have affected the trajectories of internalising and externalising symptoms followed across childhood and adolescence, over and above the effect of the covariates we considered. Fifth, our MCS-based sample did not have enough clustering at school-level, and therefore we may not have captured the 'true' between-school differences in children's internalising and externalising problems (Welsh et al. 1999). Unlike surveys about school effects which normally recruit when the children are already clustered in schools, MCS is a longitudinal survey which recruited cohort members in infancy. Although the cohort had been tightly clustered in neighbourhoods at the initial sample, the lack of clustering in primary schools reflects both residential mobility and a degree of parental choice of school even for those who have not moved. A unique strength of our study however was that MCS can be linked to school-level data from administrative sources, and also that it has detailed, longitudinal information about family background, not necessarily available in schoolbased samples. Finally, we did not estimate an effect of ethnic density because of the high level of missingness in the data available. Ethnic density might have been an important omission in our list of covariates because it has been shown to promote school belonging (Benner et al. 2008), in turn predicting socio-emotional adjustment (Georgiades et al. 2013). In the absence of an ethnic density measure, we also could not estimate cross-level interactions between individual ethnicity and school ethnic composition. Individuals can feel different if they are 'mismatched' in ethnicity, an important component of the self-concept (Phinney 1990). For example, in neighbourhoods with more ethnic diversity there is less sense of belonging (Putnam 2007). Relatedly, there is a long history of research (Faris and Dunham 1939) usually showing, on average, worse mental health among ethnic minorities who live in neighbourhoods with a low proportion of people of their own ethnic group (Shaw et al. 2012).

\section{Conclusions}

In this study on 4794 children of the MCS we examined the role of primary school composition in children's trajectories of internalising and externalising problems at ages 7 to 14 years. Our findings suggest that children in schools with a higher proportion of pupils on free school meals and those in schools with poorer academic performance have more internalising and externalising problems throughout childhood and adolescence, while those attending schools with a higher proportion of pupils with special educational needs have more internalising problems only. However, once family and individual characteristics are taken into account, only the association between attending a school with a higher proportion of pupils on free school meals and own externalising problems remains significant. Of the individual and family characteristics considered, lower academic performance, having special educational needs, having a distressed mother and not living with both biological parents are associated with more internalising and externalising problems. If the associations described are causal they suggest that interventions targeting schools with less affluent overall intakes, as well as children with these individual and family characteristics, have the potential to reduce children's internalising and externalising problems. 
Funding This study was funded by grant ES/N007921/1 from the Economic and Social Research Council.

\section{Compliance with Ethical Standards}

Conflict of Interest The authors declare that they have no conflict of interest.

Ethical Approval Ethical approval for MCS was gained from NHS Multi-Centre Ethics Committees. Ethical approval for the teacher survey was given by the Northern and Yorkshire Multi-Centre Research Ethics Committee (MREC) of the NHS. Further approvals were sought and given for carrying out the survey in schools. For England, the survey was approved by the Star Chamber in the Department for Children, Schools and Families.

Informed Consent Parents gave informed consent before interviews took place, and from age 11 children gave assent.

Open Access This article is distributed under the terms of the Creative Commons Attribution 4.0 International License (http:// creativecommons.org/licenses/by/4.0/), which permits unrestricted use, distribution, and reproduction in any medium, provided you give appropriate credit to the original author(s) and the source, provide a link to the Creative Commons license, and indicate if changes were made.

\section{References}

Anderman, E. M. (2002). School effects on psychological outcomes during adolescence. Journal of Educational Psychology, 94(4), 795809.

Angold, A., Costello, E. J., \& Worthman, C. M. (1998). Puberty and depression: The roles of age, pubertal status and pubertal timing. Psychological Medicine, 28(1), 51-61.

Arseneault, L., Bowes, L., \& Shakoor, S. (2010). Bullying victimization in youths and mental health problems:'much ado about nothing'? Psychological Medicine, 40(5), 717-729.

Azur, M. J., Stuart, E. A., Frangakis, C., \& Leaf, P. J. (2011). Multiple imputation by chained equations: What is it and how does it work? International Journal of Methods in Psychiatric Research, 20(1), 40-49.

Benner, A. D., \& Crosnoe, R. (2011). The racial/ethnic composition of elementary schools and young Children's academic and socioemotional functioning. American Educational Research Journal, 48(3), 621-646.

Benner, A. D., \& Graham, S. (2007). Navigating the transition to multiethnic urban high schools: Changing ethnic congruence and adolescents' school-related affect. Journal of Research on Adolescence, 17(1), 207-220.

Benner, A. D., \& Yan, N. (2015). Classroom race/ethnic composition, family-school connections, and the transition to school. Applied Developmental Science, 19(3), 127-138.

Benner, A. D., Graham, S., \& Mistry, R. S. (2008). Discerning direct and mediated effects of ecological structures and processes on adolescents' educational outcomes. Developmental Psychology, 44(3), $840-854$.

Bonell, C., Parry, W., Wells, H., Jamal, F., Fletcher, A., Harden, A., et al. (2013). The effects of the school environment on student health: A systematic review of multi-level studies. Health \& Place, 21, 180191.
Bronfenbrenner, U. (1979). The ecology of human development: Harvard university press.

Bronfenbrenner, U., \& Morris, P. A. (1998). The ecology of developmental processes. In W. Damon \& R. M. Lerner (Eds.), Handbook of child psychology (pp. 993-1028). New York: Wiley.

Bronfenbrenner, U., \& Morris, P. A. (2006). The bioecological model of human development. Handbook of child psychology.

Charlton, C., Rasbash, J., Browne, W., Healy, M., \& Cameron, B. (2018). MLwiN version 3.02. Bristol: Centre for Multilevel, Modelling University of Bristol.

Cicchetti, D., \& Toth, S. L. (2014). A developmental perspective on internalizing and externalizing disorders. In D. Cicchetti \& S. L. Toth (Eds.), Internalizing and externalizing expressions of dysfunction (Vol. 2, 1st ed., pp. 9-28). New York: Psychology Press.

Clarke, P., \& Wheaton, B. (2007). Addressing data sparseness in contextual population research: Using cluster analysis to create synthetic neighborhoods. Sociological Methods \& Research, 35(3), 311-351.

Cvencek, D., Fryberg, S. A., Covarrubias, R., \& Meltzoff, A. N. (2018). Self-concepts, self-esteem, and academic achievement of minority and majority north American elementary school children. Child Development, 89(4), 1099-1109.

Dicke, T., Marsh, H. W., Parker, P. D., Pekrun, R., Guo, J., \& Televantou, I. (2018). Effects of school-average achievement on individual selfconcept and achievement: Unmasking phantom effects masquerading as true compositional effects. Journal of Educational Psychology, 110(8), 1112-1126.

Dudovitz, R. N., Chung, P. J., Reber, S., Kennedy, D., Tucker, J. S., Shoptaw, S., Dosanjh, K. K., \& Wong, M. D. (2018). Assessment of exposure to high-performing schools and risk of adolescent substance use: A natural experiment. JAMA Pediatrics, 172(12), 11351144.

Faris, R. E. L., \& Dunham, H. W. (1939). Mental disorders in urban areas: An ecological study of schizophrenia and other psychoses. Oxford: Univ. Chicago Press.

Fleischmann, F., Phalet, K., Deboosere, P., \& Neels, K. (2012). Comparing concepts of ethnicity in ethnic composition measures: Local community contexts and the educational attainment of the second generation in Belgium. Journal of Ethnic and Migration Studies, 38(10), 1513-1531.

Flouri, E., \& Buchanan, A. (2003). The role of mother involvement and father involvement in adolescent bullying behavior. Journal of Interpersonal Violence, 18(6), 634-644.

Flouri, E., \& Midouhas, E. (2016). School composition, family poverty and child behaviour. Social Psychiatry and Psychiatric Epidemiology, 51(6), 817-826.

Flouri, E., Papachristou, E., Midouhas, E., Joshi, H., Ploubidis, G. B., \& Lewis, G. (2018). Early adolescent outcomes of joint developmental trajectories of problem behavior and IQ in childhood. European Child \& Adolescent Psychiatry, 27(12), $1595-1605$.

Fox, J. (2016). Applied regression analysis and generalized linear models (3rd ed.). United States of America: Sage Publications.

Gelman, A. (2008). Scaling regression inputs by dividing by two standard deviations. Statistics in Medicine, 27(15), 2865-2873.

Georgiades, K., Boyle, M. H., \& Fife, K. A. (2013). Emotional and behavioral problems among adolescent students: The role of immigrant, racial/ethnic congruence and belongingness in schools. Journal of Youth and Adolescence, 42(9), 1473-1492.

Gieling, M., Vollebergh, W., \& van Dorsselaer, S. (2010). Ethnic density in school classes and adolescent mental health. Social Psychiatry and Psychiatric Epidemiology, 45(6), 639-646.

Goodman, R. (1997). The strengths and difficulties questionnaire: A research note. Journal of Child Psychology and Psychiatry, 38(5), 581-586.

Goodman, E., Huang, B., Wade, T. J., \& Kahn, R. S. (2003). A multilevel analysis of the relation of socioeconomic status to adolescent 
depressive symptoms: Does school context matter? The Journal of Pediatrics, 143(4), 451-456.

Goodman, A., Lamping, D. L., \& Ploubidis, G. B. (2010). When to use broader Internalising and Externalising subscales instead of the hypothesised five subscales on the strengths and difficulties questionnaire (SDQ): Data from British parents, teachers and children. Journal of Abnormal Child Psychology, 38(8), 1179-1191.

Greenberg, J. H. (1956). The measurement of linguistic diversity. Language, 32(1), 109-115.

Gurin, P., Nagda, B. R. A., \& Lopez, G. E. (2004). The benefits of diversity in education for democratic citizenship. Journal of Social Issues, 60(1), 17-34.

Hienonen, N., Lintuvuori, M., Jahnukainen, M., Hotulainen, R., \& Vainikainen, M.-P. (2018). The effect of class composition on cross-curricular competences-students with special educational needs in regular classes in lower secondary education. Learning and Instruction, 58, 80-87.

Huang, Y., \& Gatenby, R. (2010). Millennium cohort study sweep 4 teacher survey technical report: London: Centre for Longitudinal Studies. Institute of Education.

Huisman, M., Araya, R., Lawlor, D. A., Ormel, J., Verhulst, F. C., \& Oldehinkel, A. J. (2010). Cognitive ability, parental socioeconomic position and internalising and externalising problems in adolescence: Findings from two European cohort studies. European Journal of Epidemiology, 25(8), 569-580.

Ilie, S., Sutherland, A., \& Vignoles, A. (2017). Revisiting free school meal eligibility as a proxy for pupil socio-economic deprivation. British Educational Research Journal, 43(2), 253-274.

Jansen, P. W., Verlinden, M., Dommisse-van Berkel, A., Mieloo, C., van der Ende, J., Veenstra, R., et al. (2012). Prevalence of bullying and victimization among children in early elementary school: Do family and school neighbourhood socioeconomic status matter? BMC Public Health, 12(1), 494.

Joshi, H., \& Fitzsimons, E. (2016). The UK millennium cohort: The making of a multipurpose resource for social science and policy. Longitudinal and Life Course Studies, 7(4), 409-430.

Kelly, D. B., Rollings, A. L., \& Harmon, J. G. (2005). Chronic selfdestructiveness, hopelessness, and risk-taking in college students. Psychological Reports, 96(3), 620-624.

Kessler, R. C., Andrews, G., Colpe, L. J., Hiripi, E., Mroczek, D. K., Normand, S.-L., et al. (2002). Short screening scales to monitor population prevalences and trends in non-specific psychological distress. Psychological Medicine, 32(6), 959-976.

Kessler, R. C., Green, J. G., Gruber, M. J., Sampson, N. A., Bromet, E., Cuitan, M., et al. (2010). Screening for serious mental illness in the general population with the $\mathrm{K} 6$ screening scale: Results from the WHO world mental health (WMH) survey initiative. International Journal of Methods in Psychiatric Research, 19(0 1), 4-22.

Konstantopoulos, S., \& Borman, G. (2011). Family background and school effects on student achievement: A multilevel analysis of the Coleman data. Teachers College Record, 113(1), 97-132.

Krueger, R. F., McGue, M., \& Iacono, W. G. (2001). The higher-order structure of common DSM mental disorders: Internalization, externalization, and their connections to personality. Personality and Individual Differences, 30(7), 1245-1259.

Le, T. N., \& Stockdale, G. (2011). The influence of school demographic factors and perceived student discrimination on delinquency trajectory in adolescence. Journal of Adolescent Health, 49(4), 407-413.

Luoma, I., Puura, K., Tamminen, T., Kaukonen, P., Piha, J., Räsänen, E., Kumpulainen, K., Moilanen, I., Koivisto, A. M., \& Almqvist, F. (1999). Emotional and behavioural symptoms in 8-9-year-old children in relation to family structure. European Child \& Adolescent Psychiatry, 8(4), S29-S40.

Macleod, J., \& Davey Smith, G. (2003). Psychosocial factors and public health: A suitable case for treatment? Journal of Epidemiology \& Community Health, 57(8), 565-570.
Marsh, H. W., \& Hau, K.-T. (2003). Big-fish-little-pond effect on academic self-concept: A cross-cultural (26-country) test of the negative effects of academically selective schools. American Psychologist, 58(5), 364-376.

Martens, P. J., Chateau, D. G., Burland, E. M., Finlayson, G. S., Smith, M. J., Taylor, C. R., et al. (2014). The effect of neighborhood socioeconomic status on education and health outcomes for children living in social housing. American Journal of Public Health, 104(11), 2103-2113.

Midouhas, E. (2017). School poverty effects on trajectories of child behaviour: Do they depend on gender and ethnicity? Health \& Place, 46, 281-292.

Milkie, M. A., \& Warner, C. H. (2011). Classroom learning environments and the mental health of first grade children. Journal of Health and Social Behavior, 52(1), 4-22.

Millings, A., Buck, R., Montgomery, A., Spears, M., \& Stallard, P. (2012). School connectedness, peer attachment, and self-esteem as predictors of adolescent depression. Journal of Adolescence, 35(4), 1061-1067.

Nye, B., Konstantopoulos, S., \& Hedges, L. V. (2004). How large are teacher effects? Educational Evaluation and Policy Analysis, 26(3), 237-257.

Oldfield, J., Humphrey, N., \& Hebron, J. (2017). Risk factors in the development of behaviour difficulties among students with special educational needs and disabilities: A multilevel analysis. British Journal of Educational Psychology, 87(2), 146-169.

Pearce, N., \& Davey Smith, G. (2003). Is social capital the key to inequalities in health? American Journal of Public Health, 93(1), 122-129.

Phinney, J. S. (1990). Ethnic identity in adolescents and adults: Review of research. Psychological Bulletin, 108(3), 499-514.

Pickett, K. E., \& Wilkinson, R. G. (2008). People like us: Ethnic group density effects on health. Ethnicity \& Health, 13(4), 321-334.

Putnam, R. D. (2007). E pluribus unum: Diversity and community in the twenty-first century the 2006 Johan Skytte prize lecture. Scandinavian Political Studies, 30(2), 137-174.

Reiss, F. (2013). Socioeconomic inequalities and mental health problems in children and adolescents: A systematic review. Social Science \& Medicine, 90, 24-31.

Richmond, T. K., \& Subramanian, S. (2008). School level contextual factors are associated with the weight status of adolescent males and females. Obesity, 16(6), 1324-1330.

Rumberger, R. W., \& Thomas, S. L. (2000). The distribution of dropout and turnover rates among urban and suburban high schools. Sociology of Education, 73(1), 39-67.

Sameroff, A. (1975). Transactional models in early social relations. Human Development, 18(1-2), 65-79.

Sawyer, S. M., Azzopardi, P. S., Wickremarathne, D., \& Patton, G. C. (2018). The age of adolescence. The Lancet Child \& Adolescent Health, 2(3), 223-228.

Sellström, E., \& Bremberg, S. (2006). Is there a "school effect" on pupil outcomes? A review of multilevel studies. Journal of Epidemiology \& Community Health, 60(2), 149-155.

Shaw, R. J., Atkin, K., Becares, L., Albor, C. B., Stafford, M., Kiernan, K. E., et al. (2012). Impact of ethnic density on adult mental disorders: Narrative review. British Journal of Psychiatry, 201(1), 11-19.

Smith, H. J., Pettigrew, T. F., Pippin, G. M., \& Bialosiewicz, S. (2012). Relative deprivation: A theoretical and meta-analytic review. Personality and Social Psychology Review, 16(3), 203-232.

Snijders, T., \& Bosker, R. (1999). Multilevel analysis: An introduction to basic and applied multilevel analysis. In: London: Sage.

Stafford, M., \& Marmot, M. (2003). Neighbourhood deprivation and health: Does it affect us all equally? International Journal of Epidemiology, 32(3), 357-366.

StataCorp, L. (2011). College Station. TX, USA. 
Stewart, E. A. (2003). School social bonds, school climate, and school misbehavior: A multilevel analysis. Justice Quarterly, 20(3), 575604

Stouffer, S. A., Lumsdaine, A. A., Lumsdaine, M. H., Williams, R. M., Jr., Smith, M. B., Janis, I. L., et al. (1949). The American soldier: Combat and its aftermath. (studies in social psychology in world war II) (Vol. 2). Princeton: Princeton University press.

Taylor, C. (2018). The reliability of free school meal eligibility as a measure of socio-economic disadvantage: Evidence from the millennium cohort study in Wales. British Journal of Educational Studies, 66(1), 29-51.

Van der Ende, J., Verhulst, F. C., \& Tiemeier, H. (2016). The bidirectional pathways between internalizing and externalizing problems and academic performance from 6 to 18 years. Development and Psychopathology, 28(3), 855-867.

Wang, M. T., \& Sheikh-Khalil, S. (2014). Does parental involvement matter for student achievement and mental health in high school? Child Development, 85(2), 610-625.

Watkins, A. M., \& Melde, C. (2016). Bad medicine: The relationship between gang membership, depression, self-esteem, and suicidal behavior. Criminal Justice and Behavior, 43(8), 1107-1126.

Weeks, M., Ploubidis, G. B., Cairney, J., Wild, T. C., Naicker, K., \& Colman, I. (2016). Developmental pathways linking childhood and adolescent internalizing, externalizing, academic competence, and adolescent depression. Journal of Adolescence, 51, 30-40.
Welsh, W. N., Greene, J. R., \& Jenkins, P. H. (1999). School disorder: The influence of individual, institutional, and community factors. Criminology, 37(1), 73-116.

West, P., Sweeting, H., \& Leyland, A. (2004). School effects on pupils health behaviours: Evidence in support of the health promoting school. Research Papers in Education, 19(3), 261-291.

Wilcox, P., Augustine, M. C., \& Clayton, R. R. (2006). Physical environment and crime and misconduct in Kentucky schools. Journal of Primary Prevention, 27(3), 293-313.

Winkleby, M., Cubbin, C., \& Ahn, D. (2006). Effect of cross-level interaction between individual and neighborhood socioeconomic status on adult mortality rates. American Journal of Public Health, 96(12), 2145-2153.

Wong, M. D., Coller, K. M., Dudovitz, R. N., Kennedy, D. P., Buddin, R., Shapiro, M. F., et al. (2014). Successful schools and risky behaviors among low-income adolescents. Pediatrics, 134(2), e389-e396.

Yngwe, M. Å., Fritzell, J., Lundberg, O., Diderichsen, F., \& Burström, B. (2003). Exploring relative deprivation: Is social comparison a mechanism in the relation between income and health? Social Science \& Medicine, 57(8), 1463-1473.

Publisher's Note Springer Nature remains neutral with regard to jurisdictional claims in published maps and institutional affiliations. 